\title{
Comparative Study on 220V AC Feed System and 300V DC Feed System for Internet Data Centers
}

\author{
Hyosung $\mathrm{Kim}^{\dagger}$ \\ ${ }^{\dagger}$ School of Electrical Electronic \& Control Eng., Kongju National University, Cheonan, Korea
}

\begin{abstract}
Internet Data Centers (IDCs), which are essential facilities in the modern IT industry, typically have scores of MW of concentrated electric loads. The provision of an Uninterruptible Power Supply (UPS) is necessary for the power feed system of IDCs owing to the need for stable power. Thus, conventional IDC AC power feed systems have three cascaded power conversion stages, (AC-DC), (DC-AC), and (AC-DC), resulting in a very low conversion efficiency. In comparison, DC power feed systems require only a single power conversion stage (AC-DC) to supply AC main power to DC server loads, resulting in comparatively high conversion efficiency and reliability [4-11]. This paper compares the efficiencies of a 220V AC power feed system with those of a 300V DC power feed system under equal load conditions, as established by the Mok-Dong IDC of Korea Telecom Co. Ltd. (KT). Experimental results show that the total operation efficiency of the $300 \mathrm{~V}$ DC power feed system is approximately $15 \%$ higher than that of the $220 \mathrm{~V}$ AC power feed system.
\end{abstract}

Key Words: DC feed system, Digital loads, Efficiency, Internet Data Center, Reliability

\section{INTRODUCTION}

Modern human culture is changing from an industrial society into an information society. The major hardware component of an information society is a digital device, with the typical example being a computer. The Electric Power Research Institute (EPRI) expects that the digital load when compared to the analog load will increase sharply to $50 \%$ in 2020, whereas it was $10 \%$ in 2000 [1]. Thus, energy efficiency for digital loads is becoming an important issue.

Internet data centers (IDC) are mainly composed of digital loads which consume very large amounts of electric energy. Korea Telecom (KT) estimated that the total amount of electric energy consumed by all of the IDCs in Korea during 2010 was 1.26 billion $[\mathrm{kWh}]$, which is equal to the amount of electric energy consumed by the industrial city of Ulsan, Korea, with a population of 1.11 million, over the same time period [2].

The typical efficiency of a conventional IDC is less than $50 \%$ [3]. IDCs commonly adopt an uninterruptible power supply (UPS) as a standby electric power system in the event that the main power grids fail to supply electric energy. Under normal operation, in an AC feed system, an AC UPS converts $\mathrm{AC}$ voltage to $\mathrm{DC}$ to store electric energy in batteries. When needed, it reconverts the DC voltage back to AC. A power supply unit (PSU) then converts the AC power to DC to supply

Manuscript received Jul. 24, 2011; revised Dec. 6, 2011

Recommended for publication by Associate Editor Se-Kyo Chung.

$\dagger$ Corresponding Author: hyoskim@kongju.ac.kr

Tel: +82-41-521-9167, Fax: +82-41-563-3689, Kongju National University School of Electrical Electronic \& Control Eng., Kongju National University, Korea
DC power to the servers. Thus, the resultant three cascading conversion stages decrease the total conversion efficiency of an AC feed system [4]-[6].

The reliability of such a conversion system in an $\mathrm{AC}$ feed system is also very low. The percentage of nonavailability in an AC feed system supported by a UPS is $10^{-6} \sim 10^{-7}[\%]$, which may not cover the required nonavailability of $10^{-9} \sim 10^{-10}[\%]$ of modern digital devices [7].

Compared to AC feed systems, the DC UPSs in DC feed systems require only a single conversion stage, as shown in Fig. 1. Furthermore, the PSUs in DC feed systems do not need to convert AC voltage into DC. Thus, only one power stage is necessary in a DC feed system, which increases the total conversion efficiency. Moreover, the reliability of a DC feed system is nearly 100 -fold higher when compared to that of an AC feed system [8]-[11].

This paper proposes a $300 \mathrm{~V}$ DC feed system instead of the conventionally used $220 \mathrm{~V}$ AC feed system for an IDC. $300 \mathrm{Vdc}$ voltage is generally safer than $220 \mathrm{Vac}$ voltage in the event of accidental human contact [12]. The distribution cables established in 220V AC feed systems can be used in 300V DC feed systems without any modifications, as the voltage stress and the current stress in $300 \mathrm{~V}$ DC feed systems are always lower than those in $220 \mathrm{~V}$ AC feed systems. Another benefit of the $300 \mathrm{~V} \mathrm{DC}$ feed system is that the legacy issues are curtailed. AC servers installed in conventional 220V AC feed systems can be used in 300V DC feed systems without any major modifications.

This paper establishes an IDC test bed for both $220 \mathrm{~V}$ $\mathrm{AC}$ and $300 \mathrm{~V}$ DC feed systems to compare the operation 


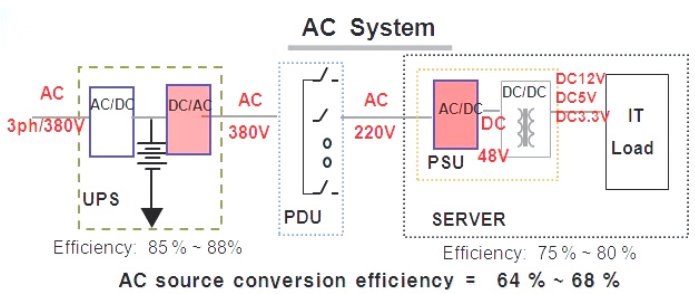

(a)

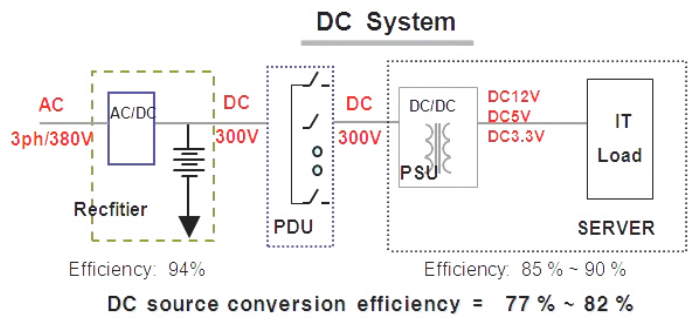

(b)

Fig. 1. Comparison of typical electric feed systems in Internet Data Centers (a) AC feed system. (b) DC feed system.

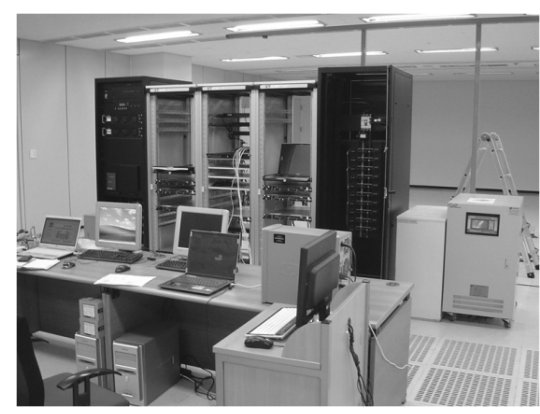

Fig. 2. Photo of the IDC test bed.

efficiencies in actual operation situations. The instantaneous power and the effective average power in both feed systems are measured and analyzed under equal server load conditions.

\section{TeChNicAl Work Preparation}

\section{A. Structure of the IDC Test Bed}

Fig. 2 shows an image of the established IDC test bed for both the 220V AC and 300V DC feed systems. Fig. 3 explains the concept of server deployment in the IDC test bed. With the two feed systems, three servers, a WEB server, a WAS server, and a storage server, are deployed equally with a SV7-2188 model manufactured by eSlim Co., Korea. Each feed system uses the same storage device used by a SANbloc's FA-1430 model.

The maximum rated power of each server is approximately $300 \mathrm{~W}$. The rated power of the PSU in the AC server is $600 \mathrm{~W}$, while that of the DC server is $400 \mathrm{~W}$. The maximum rated power of the storage device is regarded as that of the servers, i.e., $300 \mathrm{~W}$.

All of the servers installed in the IDC test bed execute tasks by a command from the Load Runner component. The Load Runner gives the same tasks to the servers connected to the $\mathrm{AC}$ and DC feed systems so as, to compare and analyze the power consumed and the power supplied by both feed systems in one business day.

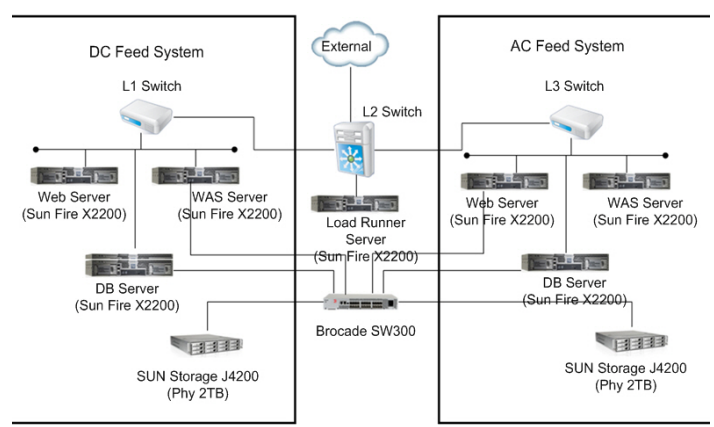

Fig. 3. Concept of server load deployment in an IDC test bed.

TABLE I

Electrical SPecifications of A DC POWER SourCe

\begin{tabular}{c|c|c}
\hline \multicolumn{2}{c|}{ Item } & Specification \\
\hline \multirow{4}{*}{ Input } & Rated Voltage & $3 \Phi 4 \mathrm{~W} / 380 \mathrm{VAC}$ \\
\cline { 2 - 3 } & Voltage variance & $\pm 10 \%$ \\
\cline { 2 - 3 } & Frequency & $60 \mathrm{~Hz} \pm 5 \%$ \\
\hline \multirow{4}{*}{ Output } & Nominal Voltage & $+300 \mathrm{Vdc}$ \\
\cline { 2 - 3 } & Rated current & $33.3 \mathrm{Adc}$ \\
\cline { 2 - 3 } & Over current & $100 \sim 110 \%$ \\
\cline { 2 - 3 } & Voltage stability & $\pm 1 \%$ \\
\cline { 2 - 3 } & Voltage range & $266 \sim 302 \mathrm{Vdc}$ \\
\cline { 2 - 3 } & Max. Efficiency & $95 \%$ \\
\hline
\end{tabular}

Table I shows the electrical specifications of the DC power source based on the DC UPS concept. The nominal DC voltage is $300 \mathrm{Vdc}$, and the rated output power is $10 \mathrm{~kW}$. The maximum efficiency of the DC power source, according to the manufacturer, is $95 \%$. Table II shows electrical specifications of the AC power source based on the AC UPS concept. The rated $\mathrm{AC}$ voltage is $220 \mathrm{Vac}$, and the rated output power is $10 \mathrm{~kW}$. The maximum efficiency of the AC power source, according to the manufacturer, is $89 \%$.

\section{B. Power Source Efficiency under a Resistive Load}

The efficiency of each power source was measured under a resistive load. Fig. 4 shows an image of the data acquisition system developed in this study to measure the efficiency. This paper uses a LabView instrumental system for data acquisition and processing. The data acquisition system samples 6,000 instances of data in one second. Thus, 100 data instances per cycle of three-phase input current and input voltage are measured and multiplied to obtain the instantaneous power and the effective average power. The output current and voltage from the both the AC feed system and the DC feed system are measured in the same way to calculate the instantaneous power and effective average power.

Fig. 5 describes the concepts of the electrical circuit diagrams for both the AC and DC feed systems in the proposed IDC test bed. The AC and DC UPSs have an equal rated power of $10 \mathrm{~kW}$, which feed AC or DC power to the corresponding AC or DC server loads. Here, the overall power capacity of either the AC or DC load is $1200 \mathrm{~W}$.

Fig. 6 shows the dissipated instantaneous power from each power source when a resistive load is applied. The instantaneous power in the $300 \mathrm{~V}$ DC feed system is clearly constant, 
TABLE II

EleCtrical SPECIFICATIONS OF AN AC POWER SOURCE

\begin{tabular}{c|c|c}
\hline \multicolumn{2}{c|}{ Item } & Specification \\
\hline \multirow{4}{*}{ Input } & Rated Voltage & $3 \Phi 4 \mathrm{~W} / 380 \mathrm{VAC}$ \\
\cline { 2 - 3 } & Voltage variance & $\pm 10 \%$ \\
\cline { 2 - 3 } & Frequency & $60 \mathrm{~Hz} \pm 5 \%$ \\
\hline \multirow{5}{*}{ Output } & Nominal Voltage & $1 \Phi / 220$ Vac_rms \\
\cline { 2 - 3 } & Rated current & $45 \mathrm{Aac} \_$rms \\
\cline { 2 - 3 } & Power factor & $90 \%$ \\
\cline { 2 - 3 } & Voltage stability & $\pm 3 \%$ \\
\cline { 2 - 3 } & Voltage range & $200 \sim 220$ Vac_rms \\
\cline { 2 - 3 } & Max. Efficiency & $89 \%$ \\
\hline
\end{tabular}

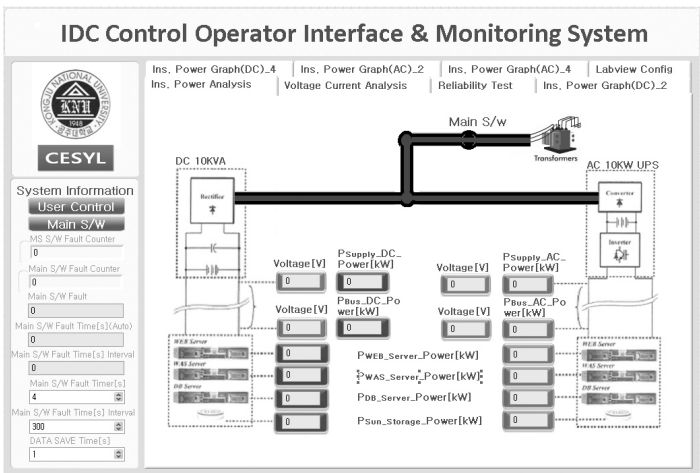

Fig. 4. Photo of the data acquisition and processing system by LabView.

whereas the power in the $220 \mathrm{~V}$ AC feed system fluctuates with a cycle of twice the line frequency. When the effective average powers from both feed systems are equal, the $220 \mathrm{~V}$ AC feed system should supply twice as much instantaneous peak power as the $300 \mathrm{~V}$ DC feed system. This means that the $220 \mathrm{~V}$ AC feed system requires a conversion capacity that is double that of the $300 \mathrm{~V}$ DC feed system.

Fig. 7 shows the results of the efficiency analyses for both feed systems under a resistive load. Here, an additional 100mlength feed cable was deployed between the power source and the load to analyze the power loss and voltage drop through the feed cable. In Fig. 6, the upper curve represents the efficiency of the $100 \mathrm{~m}$-length feed cable, the middle curve represents the efficiency of the power converter itself, and lower curve represents the total efficiency of both the power converter and the $100 \mathrm{~m}$-length feed cable. The total efficiency of the $300 \mathrm{~V}$ DC feed system reaches its maximum at around $90 \%$, while that of the $220 \mathrm{~V}$ AC feed system reaches its maximum at around $86 \%$.

Fig. 8 shows the results of the analysis of the voltage drop on both of the feed cables under a resistive load. For feed cables with an equal cross-sectional size, the voltage drop in the $\mathrm{AC}$ feed cable is 1.5 times higher than that of the DC feed cable. This stems from the fact that the RMS current in the $220 \mathrm{~V}$ AC feed system is higher than that in the $300 \mathrm{~V}$ DC feed system under an equal load power. The rated current of both feed systems can be calculated by Eqs. (1) and (2).

$$
I_{\text {DCRate }}=\frac{P_{\text {DCRate }}}{V_{\text {DCRate }}}=\frac{P_{D C \text { Rate }}}{300}
$$

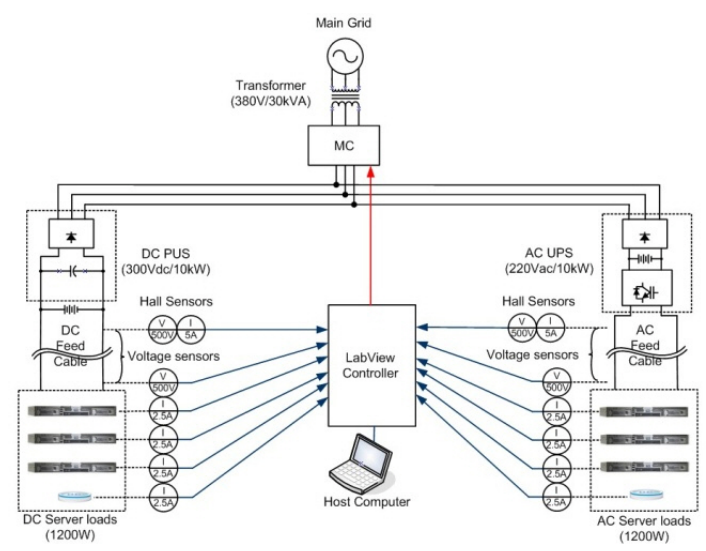

Fig. 5. Electrical circuit diagram of the feeding systems in the IDC test bed.

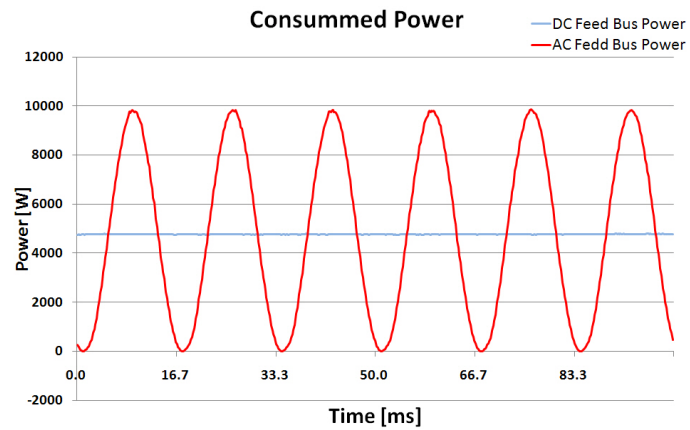

Fig. 6. Instantaneous power at the feed bus under a resistive load.

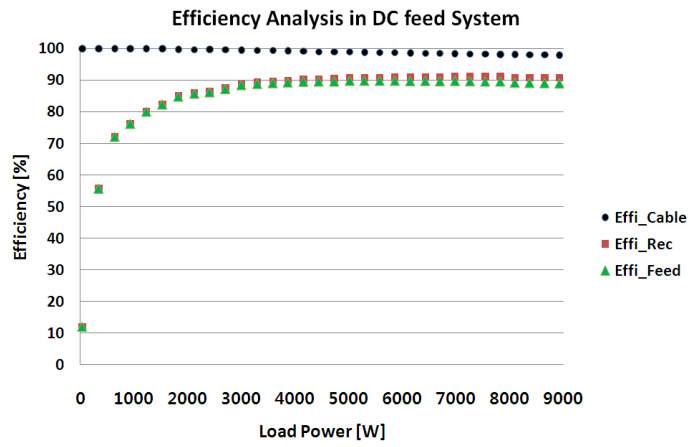

(a)

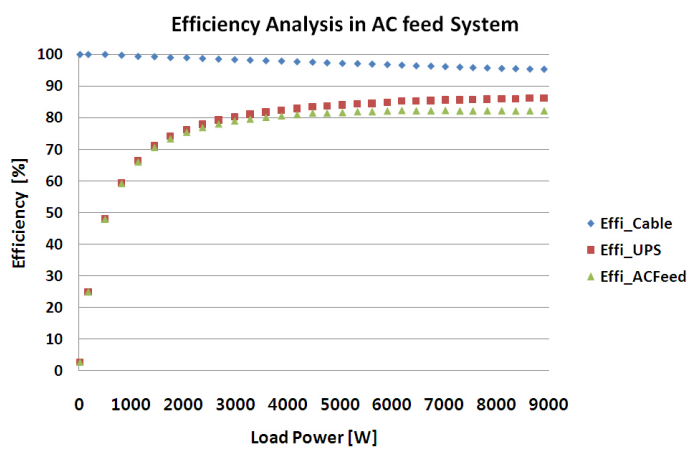

(b)

Fig. 7. Efficiency at the feed bus under a resistive load. (a) DC feed system. (b) AC feed system. 


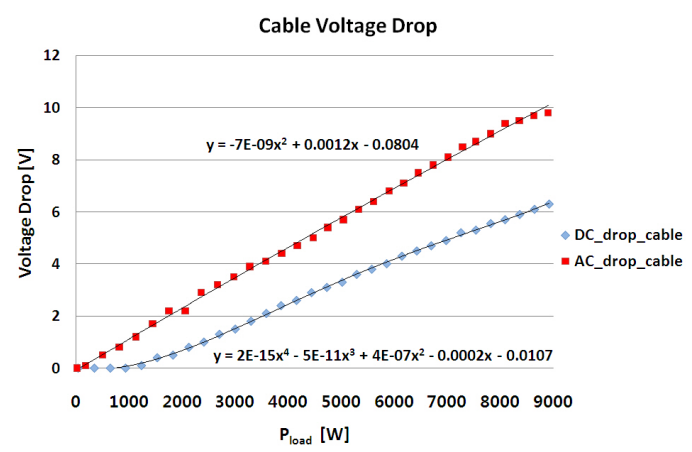

Fig. 8. Voltage drop on the feed cable under a resistive load.

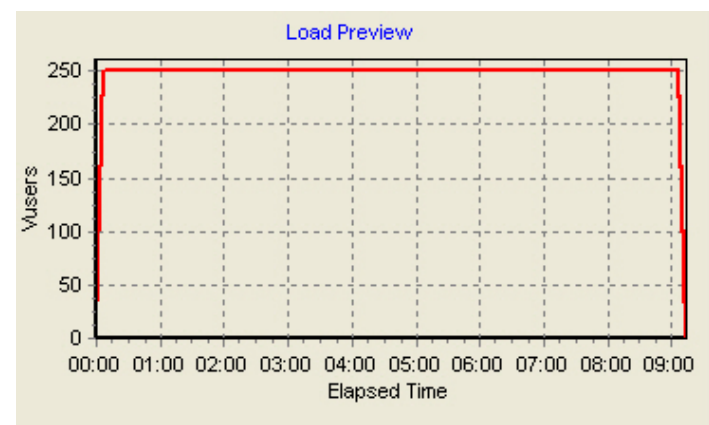

Fig. 9. Artificial user profile commanded by Load Runner.

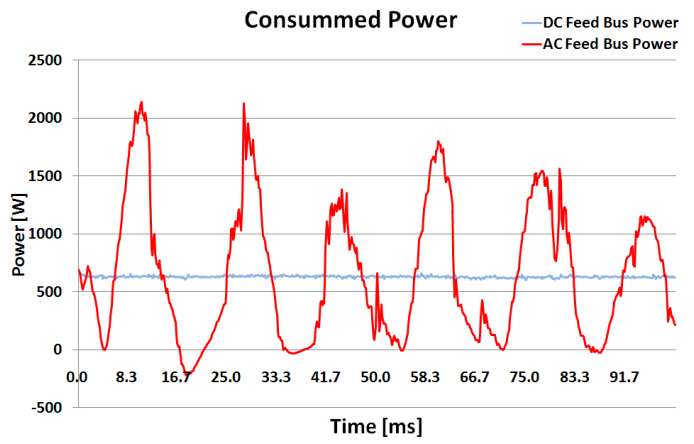

Fig. 10. Instantaneous power at the feed bus under the no-operation server load condition.

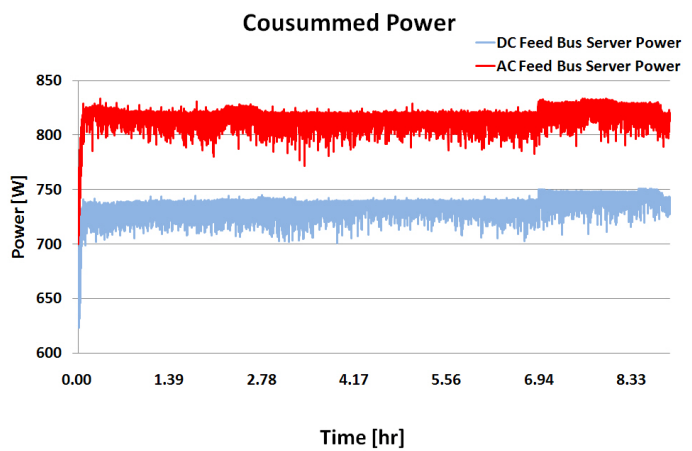

Fig. 11. Active power profile at the feed bus during server operation by Load Runner.

$$
I_{\text {ACRate }}=\frac{P_{\text {ACRate }}}{V_{\text {ACRate }}}=\frac{P_{\text {ACRate }}}{220} .
$$

When the rated powers in both feed systems are equal, the rated current ratio between the two feed systems can be calculated by Eq. (3).

$$
\frac{I_{\text {ACRate }}}{I_{\text {DCRate }}}=\frac{V_{\text {DCRate }}}{V_{\text {ACRate }}}=\frac{300}{220} \approx 1.36 .
$$

Another likely reason for the voltage drop difference stems from the skin effect, which increases the voltage drop in the AC feed cable.

\section{Power Source Efficiency at Real Server Load}

In this study, the rated maximum server load is $1.2 \mathrm{~kW}$ while the power source capacity is $10 \mathrm{~kW}$. Thus, the server loads cover only about $10 \%$ of the source capacity. Hence, the actual operation efficiency can be measured only under a light load condition. To analyze the actual operation efficiency over the entire power range of the power source, the power losses in both feed systems were normalized on a per unit basis. The dissipated powers in the servers were also normalized on a per unit basis. Thus, the efficiency over the entire range of the power converter can be calculated properly under the actual operation conditions of the server loads [8].

Fig. 9 shows the artificial user profile that was commanded by the Load Runner in this research. After start up, the Load Runner increases the number of artificial users to 250 people and continues the trial for up to 9 hours. The Load Runner then lets the artificial users access the server and hard disk resources from each feed system, to increase the amount of power consumed as a digital load from both the AC and DC feed systems equally.

This experimental result shows that the server loads in the $220 \mathrm{~V}$ AC feed system dissipate more active power when compared to the $300 \mathrm{~V}$ DC feed system, even under a nooperation condition. The explanation for this is the same as that for the previously mentioned power source efficiency analysis under a resistive load; a higher RMS current value and the skin effect in the $220 \mathrm{~V}$ AC feed system. Therefore, the power converter in the $220 \mathrm{~V}$ AC feed system should be designed to be three times larger than that of the $300 \mathrm{~V}$ DC feed system, as the instantaneous power in the $220 \mathrm{~V} \mathrm{AC}$ feed system can reach up to three times that of the $300 \mathrm{~V}$ DC feed system.

Fig. 11 shows the active power profile that is dissipated in all of the server loads in both of the feed systems when 250 artificial users are allocated by the Load Runner. Although the tasks for the servers in both feed systems are identical, the dissipated power in the $220 \mathrm{~V}$ AC feed system is generally higher than that in the $300 \mathrm{~V}$ DC feed system.

Fig. 12 shows the power loss for both of the feed systems against the dissipated power, as represented in a per unit basis. The loss functions for each of the power loss curves are obtained in second-order polynomial form by the least square regression method. The loss functions can be used to calculate the power loss in each of the feed systems for any server load [14]. 


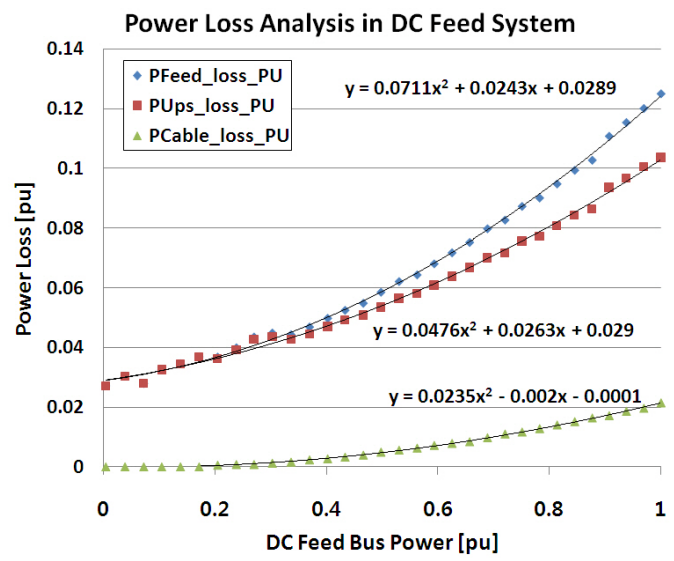

(a)

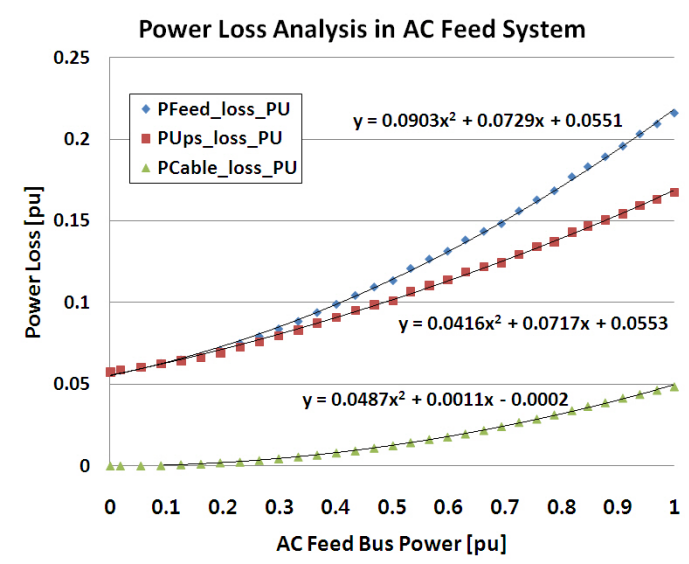

(b)

Fig. 12. Per Unit loss function against dissipated power. (a) DC Feed system. (b) AC Feed system.

TABLE III

EFFICIENCY COMPARISON BETWEEN THE Two FEED SyStems

\begin{tabular}{c|c|c}
\hline & DC feed system & AC feed system \\
\hline Short Cable $(1 \mathrm{~m})$ & $90.19 \%$ & $83.61 \%$ \\
\hline Long Cable $(100 \mathrm{~m})$ & $89.44 \%$ & $81.74 \%$ \\
\hline
\end{tabular}

From the regression curves obtained in Fig. 12, the power loss in each of the feed systems can be calculated on a per unit basis via the following loss functions:

\section{At 100m DC feed cable:}

puLoss $=0.0235 \times(\text { puLoad })^{2}-0.002 \times($ puLoad $)+0.0001$

\section{At DC UPS:}

$$
\text { puLoss }=0.0476 \times(\text { puLoad })^{2}-0.0263 \times(\text { puLoad })+0.029
$$

Both 100m DC feed cable and DC UPS:

$$
\text { puLoss }=0.0711 \times(\text { puLoad })^{2}-0.0243 \times(\text { puLoad })+0.0289
$$

\section{At $100 \mathrm{~m}$ AC feed cable:}

$$
\text { puLoss }=0.0487 \times(\text { puLoad })^{2}-0.0011 \times(\text { puLoad })+0.0002
$$

\section{At AC UPS:}

$$
\text { puLoss }=0.0416 \times(\text { puLoad })^{2}-0.0717 \times(\text { puLoad })+0.0553
$$

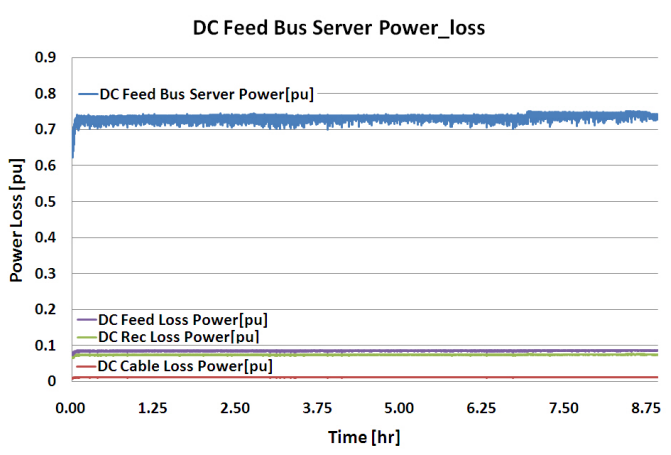

(a)

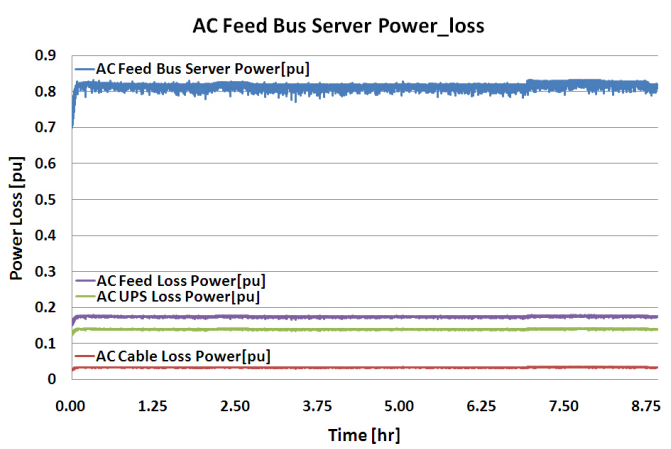

(b)

Fig. 13. Per unit power analysis of the power source against the server loads. (a) DC feed system. (b) AC feed system.

TABLE IV SPECIFICATIONS OF THE AC AND DC PSU

\begin{tabular}{c|c|c}
\hline & AC server PSU & DC server PSU \\
\hline Manufacture & DELTA & IDKorea \\
\hline Model No. & TDPS-600CB B & IDSDC400L-A1 B \\
\hline Input condition & AC 90 264V/ 600W & DC 230 330V/ 400W \\
\hline & - Active PFC & - NO PFC Circuit \\
& - Pull-Bridge Converter & - Two-Switch Active \\
Characteristics & with Synchronous & clamp Forward with \\
& Rectifier. & Diode Rect. \\
& - Cooling Fan $\times 2 \mathrm{EA}$ & - Cooling Fan $\times 2 \mathrm{EA}$ \\
\hline
\end{tabular}

TABLE V

PSU EFFICIENCY FOR THE AC SERVER AND THE DC SERVER

\begin{tabular}{c|c|c|c|c}
\hline \multirow{2}{*}{} & \multicolumn{2}{|c|}{ DC Feed System } & \multicolumn{2}{c}{ AC Feed System } \\
\cline { 2 - 5 } & $\begin{array}{c}\mathrm{E}_{\text {Input }} \\
{[\mathrm{Wh}]}\end{array}$ & $\begin{array}{c}\mathrm{E}_{\text {Output }} \\
{[\mathrm{Wh}]}\end{array}$ & $\begin{array}{c}\mathrm{E}_{\text {Input }} \\
{[\mathrm{Wh}]}\end{array}$ & $\begin{array}{c}\mathrm{E}_{\text {Out put }} \\
{[\mathrm{Wh}]}\end{array}$ \\
\hline $\begin{array}{c}\text { WEB } \\
\text { server PSU }\end{array}$ & $1,738.92$ & $1,430.47$ & $2,144.83$ & $1,471.78$ \\
\hline $\begin{array}{c}\text { WAS } \\
\text { server PSU }\end{array}$ & $1,859.95$ & $1,551.70$ & $2,146.59$ & $1,517.06$ \\
\hline $\begin{array}{c}\text { DB server } \\
\text { PSU }\end{array}$ & $1,954.43$ & $1,635.37$ & $2,144.92$ & $1,645.34$ \\
\hline $\begin{array}{c}\text { Total } \\
\text { PSU } \\
\text { Efficiency } \\
{[\%]}\end{array}$ & $5,553.30$ & $4,617.54$ & 6436.34 & 4634.18 \\
\hline \multicolumn{2}{|c|}{83.15} & \multicolumn{2}{c}{72.00} \\
\hline
\end{tabular}


Both $100 m$ AC feed cable and AC UPS:

$$
\text { puLoss }=0.0903 \times(\text { puLoad })^{2}-0.0729 \times(\text { puLoad })+0.0551
$$

where, puLoad is the consumed power at server loads represented on a per unit basis, while puLoss is the dissipated power loss in the corresponding power feeding facilities, such as the feed cable and UPS, represented on a per unit basis.

By applying the loss functions obtained in Eqs. (4)-(9) to the active power profile obtained in Fig. 12, the per unit power components of the server load power, feed cable loss power, and UPS loss power can be calculated, as shown in Fig. 13. Thus, the power source efficiency, $h_{\text {source }}$, is calculated by Eq. (10).

$$
\eta_{\text {source }}=\frac{\int(\text { puLoad }) \cdot d t}{\int(\text { puLoad }+ \text { puLoss }) \cdot d t} \times 100[\%] .
$$

Table III tabulates the result of the efficiency analysis based on the previously mentioned loss functions. The total server load is $1,200 \mathrm{~W}$ while the power capacity of each of the feed systems is scaled to $1,500 \mathrm{~W}$. Two cable conditions are considered. The first case is a $1 \mathrm{~m}$ feed cable (Short Cable) and the second case is a $100 \mathrm{~m}$ feed cable (Long Cable). However, the proposed efficiency analysis can be applied for any length of feed cable in any real situation.

\section{PSU Efficiency}

Table IV shows the outside view and the data for the PSU installed in the servers of the IDC test bed. The AC PSU has a capacity of $600 \mathrm{~W}$ and can receive $\mathrm{AC}$ voltage that ranges from $90 \mathrm{Vac}$ to $264 \mathrm{Vac}$. The DC PSU has a capacity of $400 \mathrm{~W}$ and can receive DC voltage that ranges from $230 \mathrm{Vdc}$ to $330 \mathrm{Vdc}$.

There are three major types of DC output terminals in DC and AC PSUs: $3.3 \mathrm{~V}, 5 \mathrm{~V}$, and $12 \mathrm{~V}$ outputs. The DC and AC PSUs are swapped by specially modified PSUs that are equipped with current and voltage sensors at each of the three DC output terminals to measure the actual dissipated power during real operation conditions. Fig. 14 shows a photo of the specially modified PSU in this paper.

Using the specially modified PSUs, the total electrical input energy and the total electrical output energy of the PSUs in each of the feed systems in the IDC test bed can be measured directly, as can be seen in Fig. 15. Therefore, the PSU efficiency, $h_{P S U}$, can be calculated by Eq. (11).

$$
\eta_{P S U}=\frac{\sum_{i=1}^{3} E_{P S U \text { Total output }}^{i}}{\sum_{i=1}^{3} E_{P S U \text { input }}^{i}} \times 100[\%] .
$$

Table V shows the average PSU efficiency when the servers in both feed systems are operated by the Load Runner for 9 hours. The average PSU efficiency in the $300 \mathrm{~V}$ DC feed system was determined to be $83 \%$, while that in the $220 \mathrm{~V} \mathrm{AC}$ feed system was measured as $72 \%$. Thus, the average PSU efficiency of the DC feed system is around $11 \%$ higher than that of the AC feed system.
TABLE VI

EFFICIENCY COMPARISON BETWEEN THE TwO FEED Systems

\begin{tabular}{c|c|c|c}
\hline \multicolumn{2}{c|}{} & $\begin{array}{c}\text { DC Feed } \\
\text { System }\end{array}$ & $\begin{array}{c}\text { AC Feed } \\
\text { System }\end{array}$ \\
\hline \multicolumn{2}{c}{ Server PSU efficiency [\%] } & 83.15 & 72.00 \\
\hline $\begin{array}{c}\text { Power source } \\
\text { efficiency [\%] }\end{array}$ & $100 \mathrm{~m}$ Cable & 90.19 & 83.61 \\
\cline { 2 - 4 } & $1 \mathrm{~m}$ Cable & 89.44 & 81.74 \\
\hline $\begin{array}{c}\text { Total feeding } \\
\text { efficiency [\%] }\end{array}$ & $100 \mathrm{~m}$ Cable & 75.0 & 60.2 \\
\cline { 2 - 4 } & $1 \mathrm{~m}$ Cable & 74.4 & 58.9 \\
\hline
\end{tabular}

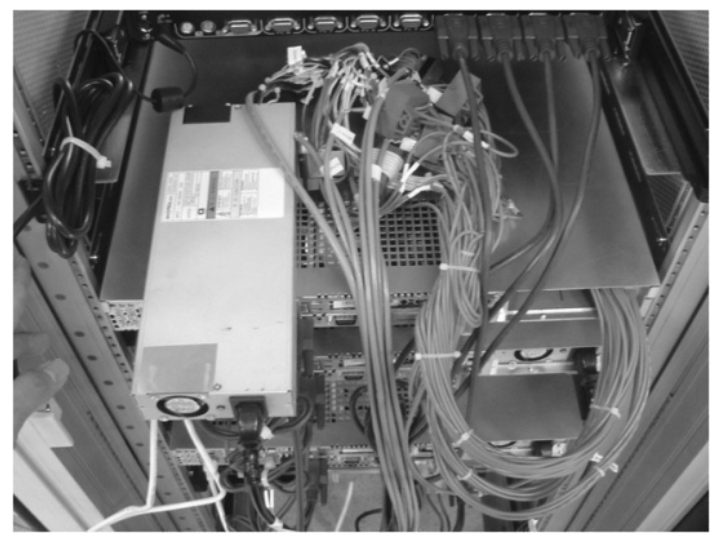

Fig. 14. Outside view of the specially modified PSU.

\section{E. Total Feed Efficiency}

At this point, the total feed efficiency, $h_{\text {Total }}$, can be calculated by Eq. (12).

$$
\eta_{\text {Total }}=\eta_{\text {source }} \times \eta_{P S U}[\%] .
$$

Applying the power source efficiency calculated in Table III and the PSU efficiency calculated in Table V, the total feeding efficiency in both feed systems for the IDC test bed were calculated, as shown in Table VI. According to the analysis results, the total feed efficiency of the $300 \mathrm{~V}$ DC feed system is $14.8 \% \sim 15.5 \%$ higher than that of the $220 \mathrm{~V}$ AC feed system.

\section{CONCLUSIONS}

This paper proposed a $300 \mathrm{~V}$ DC feed system instead of the conventionally used $220 \mathrm{~V}$ AC feed system to increase the total feeding efficiency of IDCs, which consume a great deal of electricity. The efficiencies of each of the feed systems were measured and analyzed during the actual operation of a smallscale IDC test bed installed at the Mok-Dong IDC of Korea Telecom Co. Ltd. (KT). The experimental results showed that the total feeding efficiency of the $300 \mathrm{~V}$ DC feed system was approximately $15 \%$ higher than that of the conventional $220 \mathrm{~V}$ $\mathrm{AC}$ feed system. Using feed cables of an equal cross-sectional size, the voltage drop in the $300 \mathrm{~V}$ DC feed system was nearly $50 \%$ lower than that in the conventional $220 \mathrm{~V}$ AC feed system under equal load conditions. The requirement for the converter size in the 220V AC feed system in IDCs is up to three times larger than that in the $300 \mathrm{~V}$ DC feed system.

\section{ACKNOWLEDGMENT}

This work was supported by a grant from the Korean Ministry of Education, Science and Technology (The Regional 


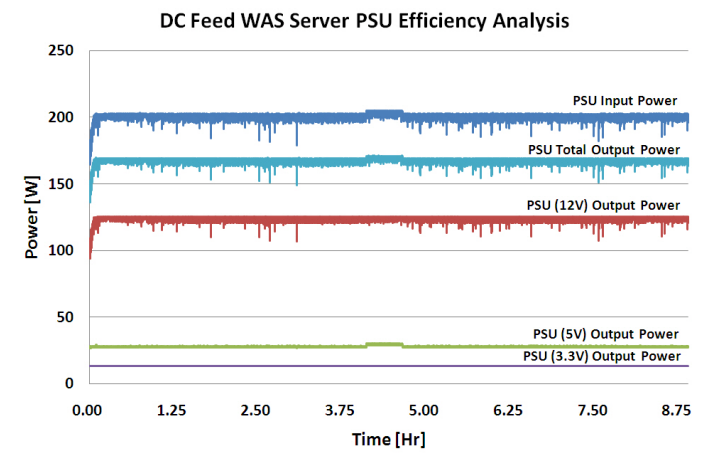

(a)

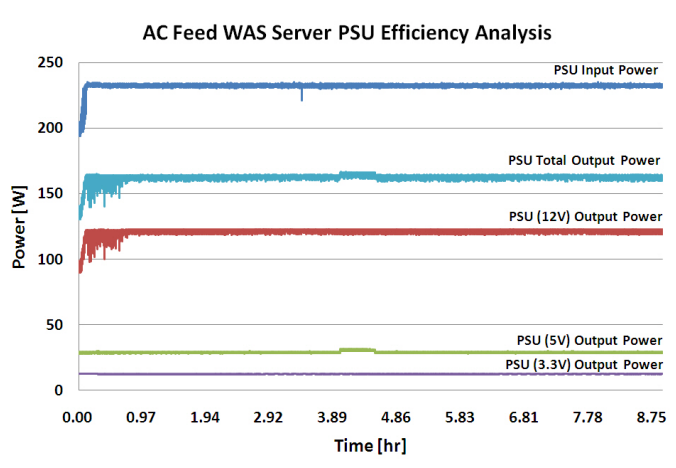

(b)

Fig. 15. Power analysis of the PSU against server loads during 9 hours of operation. (a) DC feed system. (b) AC feed system.

Core Research Program/Zero Energy Green Village Technology Center). It was also supported by a grant from the Next-Generation IDC Test Bed Based on Green Computing Infrastructure and Greenware project, No. 10035324.

\section{REFERENCES}

[1] C. W. Gellings, M. Samotyj, "Electric Infrastructure to Power a Digital Society," IEEE Power Engineering Review, pp. 15-17, Jan. 2002

[2] Next generation IDC test bed based on Green-Infra and Green-Ware, Accomplishment of Green/Cloud computing 2010 MKE project, Nov. 2010(Korean).

[3] A. Pratt, P. Kumar, and T. V. Aldridge, "Evaluation of 400V DC distribution in telco and data centers to improve energy efficiency," INTELEC 2007, pp. 32-39, Oct. 2007.
[4] M. Amin, Y. Arafat, S. Lundberg, and S. Mangold, "Low voltage DC distribution system compared with $230 \mathrm{~V}$ AC," EPEC 2011, pp. 340$345,2011$.

[5] H. Kakigano, M. Nomura, and T. Ise, "Loss evaluation of DC distribution for residential houses compared with AC system," IPEC 2010, pp. 480-486, 2010.

[6] K. G. Postiglione, DC Distribution System for Home and Office, Master's Thesis in the Department of Electric Power Engineering, Chalmers, Gothenburg, Sweden, 2001.

[7] J. G. Ciezki and R. W. Ashton, "Selection and stability issues associated with a navy shipboard DC zonal electric distribution system," IEEE Trans. Power Del., Vol. 15, No. 2, pp. 665-669, Apr. 2000.

[8] V. Sithimolada and P. W. Sauer, "Facility-level DC vs. typical ac distribution for data centers: A comparative reliability study," TENCON 2010, pp. 2102-2107, 2010.

[9] D. Marquet, G. Kervarrec, and O. Foucault, "New flexible powering architecture for integrated service operators," Intelec 2005, pp. 575-580, 2005.

[10] K. Asakura and T. Babasaki, "Proposed specifications of power feeding systems," International Telecommunication Union Study Group 5Contribution 92, Jan. 2010.

[11] J. Humphreys and J. Yang, "Server innovations: examining dc power as an alternative for increasing data center efficiency and reliability," IDC White Paper, pp. 1-7, 2004.

[12] IEC60479-1, Effects of current on human beings and livestock - Part 1: General aspects.

[13] T. Babasaki, "Developing of Higher Voltage Direct-Current Powerfeeding Prototype System," Intelec'09, pp. 1-5, 2009.

[14] N. Rasmussen, "Electrical Efficiency Modeling of Data Centers," APC White Paper \#113, Revision 1, http://www.apcmedia.com/salestools/NRAN-66CK3 DR1 EN.pdf

[15] K. Hirose, "DC Power Demonstrations in Japan," ICPE 2011-ECCE Asia, pp. 242-247, May 2011

[16] K. Asakura, J. Inamori, K. Murai, T. Tanaka, and T. Babasaki, "Development of higher-voltage direct current power feeding system in telecommunications buildings and data centers," ICPE 2011-ECCE Asia, pp. 2005-2009. May 2011.

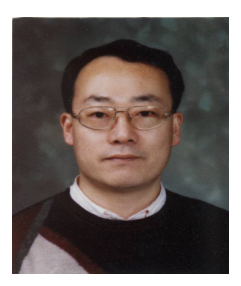

Hyosung Kim (S'90-M'96) received his B.S. and M.S. in Electrical Engineering from Seoul National University, Korea, in 1981 and 1983, respectively, and his Ph.D. from Chungbuk National University, Korea, in 1995. From 1982 to 1986, he was employed at the TongYang Cement Mfg. Co., Korea, where he participated in the factory automation and energy saving project. From 1996 to 1997, he was a Visiting Scholar in the Department of Electrical Engineering at Okayama University, Japan. From 2000 to 2001, he was an Associate Research Professor in the Institute of Energy Technology at Aalborg University, Denmark. From 1997 to the present, he has been a tenured Professor in the School of Electrical and Electronics Engineering at Kongju National University, Korea. His current research interests include power quality, static compensators, renewable energy, and DC micro grids. 